\title{
Review
}

Acta Haematol 2019;142:37-43

Received: November 22, 2018

DOI: $10.1159 / 000496140$

\section{Posttransplantation Anemia in Kidney Transplant Recipients}

\author{
Anat Gafter-Gvilia, b, d Uzi Gafter ${ }^{c, d}$ \\ ${ }^{a}$ Department of Medicine A, Rabin Medical Center, Beilinson Campus, Petah Tikva, Israel; ${ }^{b}$ Institute of Hematology, \\ Davidoff Cancer Center, Rabin Medical Center, Beilinson Campus, Petah Tikva, Israel; ' Nephrology and Transplantation \\ Immunology Laboratory, Rabin Medical Center, Petah Tikva, Israel; ${ }^{d}$ Sackler Faculty of Medicine, Tel Aviv University, \\ Tel Aviv, Israel
}

\section{Keywords}

Anemia $\cdot$ Kidney transplant $\cdot$ Posttransplantation anemia

\begin{abstract}
Posttransplantation anemia (PTA) is common among kidney transplant patients. Early PTA is usually defined as anemia which develops up to 6 months after transplantation, and late PTA is defined as anemia which develops after 6 months. There are multiple causes, with iron deficiency being the major contributor. The occurrence of late PTA has been associated with impaired graft function. Early PTA has been shown to be a predictor of late PTA. PTA is associated with reduced mortality, reduced graft survival, and a decline in GFR. The association with mortality is related to the severity of the anemia and to specific causes of anemia. Treatment of PTA should probably begin as soon as possible after kidney transplantation. The optimal target hemoglobin level in kidney transplant recipients with anemia is higher than recommended in chronic kidney disease and should probably be up to $12.5-13 \mathrm{~g} / \mathrm{dL}$. In order to achieve this target, appropriate treatment with erythropoiesis-stimulating agents (ESA) and iron is indicated.

(c) 2019 S. Karger AG, Basel
\end{abstract}

\section{Introduction}

Posttransplantation anemia (PTA) is common among kidney-transplant patients, with a prevalence of $20-51 \%$ at various time points after transplantation [1-4].

PTA has been shown to be negatively associated with the following long-term outcomes: increased rates of allcause mortality $[1,2,5-7]$, graft failure $[3,8,9]$, congestive heart failure [10], left ventricular hypertrophy [11], and a decline in the estimated glomerular filtration rate (eGFR) [1, 12].

In this review, we provide updated information regarding the prevalence of PTA in kidney transplant recipients and the causative and predictive factors. The effect of anemia on long-term outcomes, such as graft failure, kidney function, and mortality, is discussed. Treatment options are addressed as well. Better awareness and understanding of this serious accompanying comorbidity in kidney transplant recipients may potentially improve patient management.

\section{Prevalence and Epidemiology}

Although successful kidney transplantation may correct anemia, up to $20-51 \%$ of patients remain anemic after transplantation at various time points $[1-4,13]$.

Anat Gafter-Gvili, MD

Department of Medicine A and Institute of Hematology, Rabin Medical Center Beilinson Campus, 39 Jabotinsky street

Petah Tikva 49100 (Israel)

E-Mail anatga2@clalit.org.il 
PTA is not defined uniformly either in terms of timing after transplantation or in terms of the degree of anemia. However, most authors suggest distinguishing between early PTA (up to 6 months after transplantation) and late PTA (after 6 months) $[4,13,14]$.

Anemia in most studies is defined as hemoglobin $(\mathrm{Hb})$ levels $<12 \mathrm{~g} / \mathrm{dL}$ in women and $<13 \mathrm{~g} / \mathrm{dL}$ in men, in accordance with World Health Organization (WHO) criteria and the American Society of Transplantation $[15,16]$.

The prevalence of early PTA is about $50 \%$ according to various studies $[1,4,17,18]$ and the prevalence of late PTA declines to about $23-35 \%$ at various time points up until 8 years after transplantation [1, 2, 4, 12, 13, 17-19].

\section{Causes of and Predictive Factors for PTA}

Early PTA is usually due to iron deficiency. Iron deficiency may be caused by depletion of iron stores before transplantation, perioperative blood loss, and poor nutrition $[20,21]$. In addition, increased iron utilization with the onset of erythropoiesis with slowly increasing levels of the newly graft-produced erythropoietin may contribute to the anemia $[22,23]$.

Late PTA is usually defined as anemia that occurs more than 6 months after transplantation, and it can appear as late as up to 8 years later $[5,24]$. The occurrence of late PTA has been associated with impaired graft function and the development of renal insufficiency [17]. Late PTA is predominantly influenced by a reduced allograft function. However, other factors, i.e., iron deficiency, inflammation and infection, immunosuppressive medications (mycophenolate mofetil, mycofenolic acid, and azathioprione), medications affecting the renin-angiotensin-aldosterone system such as angiotensin-converting enzyme inhibitors and angiotensin receptor blockers, antimicrobial agents such as trimethoprim-sulfamethoxazole, and antiviral agents such as ganciclovir, may contribute to the anemia $[13,24,25]$.

\section{Predictors of PTA}

Several studies have aimed to find predictors of PTA. In a retrospective study by our group [1], 266 patients who underwent kidney transplantation at the Rabin Medical Center in Israel, a single tertiary center, during a 4-year period (2008-2011) were included. In a multivariate analysis, factors associated with early PTA included: female sex (HR 3.13; 95\% CI 1.18-8.28), lower eGFR (HR 0.97; 95\% CI $0.95-0.99$, for every increment of $1 \mathrm{ml} /$ $\min / 1.73 \mathrm{~m}^{2}$ ), and hypochromic red blood cells (HR
1.053; 95\% CI 1.001-1.11). Factors significantly associated with late PTA (2 years after transplantation) included early PTA, (HR 0.601; 95\% CI 0.453-0.799, for every increment of $1 \mathrm{~g} / \mathrm{dL}$ ), and a living donor as the transplantation source was protective (HR 0.343; 95\% CI $0.142-$ 0.831). In The TRansplant European Survey on Anemia Management (TRESAM) [4], data from 72 transplant centers in 16 countries, involving 4,263 kidney transplant recipients, were collected. There was a strong association between $\mathrm{Hb}$ and graft function; of the 904 patients with serum creatinine levels $>2 \mathrm{mg} / \mathrm{dL}, 60.1 \%$ were anemic, compared to $29.0 \%$ of those with serum creatinine levels $<2 \mathrm{mg} / \mathrm{dL}(p<0.01)$. Elevated serum creatinine levels $>2 \mathrm{mg} / \mathrm{dL}$ were associated with late PTA (OR 3.48; 95\% CI 2.92-4.14). Other factors that were associated with PTA included: donor age (particularly above 60 years), the use of ACE inhibitors or angiotensin receptor blockers, the use of immunosuppressive drugs such as mycophenolate mofetil and azathioprine, and a recent infection.

In another retrospective series of 626 patients who underwent transplantation in a single-center cohort from Pennsylvania, USA, factors significantly associated with late PTA (12 months) on multivariate analysis include early PTA (anemia 3 months after transplantation), donor age, 3-month creatinine levels, and female sex [6]. Similarly, another retrospective series of 192 consecutive kidney transplant recipients from a referral center in Michigan, USA, demonstrated that female sex and 3-month creatinine levels are predictors of late PTA [19].

The observation that early PTA is a predictor of late PTA $[1,6]$ possibly suggests that better prevention and treatment of early PTA might prevent late PTA.

\section{Etiology of PTA}

Iron deficiency is the most common contributing factor for early PTA. Inadequate iron stores at the time of transplantation, blood loss during surgery, increased iron utilization with the onset of erythropoiesis, and poor nutrition all contribute to the occurrence of iron deficiency [21]. Studies have confirmed that iron deficiency is the most common contributor to late PTA. In a recent study conducted in a single university center in Groningen, The Netherlands, which included 700 renal transplant recipients at least 1 year after transplantation, the prevalence of anemia was $34 \%$, that of iron deficiency anemia was $13 \%$, and that of iron deficiency without anemia was 30\% [26].

In order to define specific causes of PTA, a large retrospective cohort study from the Rabin Medical Center (RMC) transplantation department registry was con-
38

Acta Haematol 2019;142:37-43 DOI: $10.1159 / 000496140$
Gafter-Gvili/Gafter 
ducted; 1,139 patients who underwent transplantation between the years 2002 and 2016 [2] were analyzed. This study assessed late PTA, with a longitudinal analysis considering all anemia events which occurred at any time between 6 and 18 months after transplantation. The prevalence of anemia was $36 \%$. The most common causes of late PTA were nutritional deficiencies, which accounted for $61 \%$ of cases. The most common deficiency was iron deficiency, diagnosed in $34.7 \%$ ( $13 \%$ of the cohort) of the cases.

Vitamin $B_{12}$ deficiency was reported to be the cause of PTA in $17-24 \%$ of patients in several studies [2, 27-29].

Folic acid deficiency was the cause of anemia in $10 \%$ of the cases in the study by our group [2], which is a relatively low rate compared to the $23-41 \%$ reported in other studies $[25,27,28]$.

Other causes of PTA in our cohort included acute kidney injury, accounting for $11.4 \%$ of cases, and acute rejection, accounting for $4 \%$ of cases. Infections were the cause of anemia in $19 \%$ of cases [2].

\section{Outcomes of Patients with PTA}

\section{Mortality and Graft Failure}

PTA has previously been shown to be associated with the composite outcome of all-cause mortality and graft loss. However, while almost all of the studies have shown a significant correlation with graft failure, results regarding the association between anemia and mortality are inconsistent.

Several studies have documented an association with mortality. A retrospective multicenter analysis using a French database that included 4,217 transplant recipients showed that PTA at 12 months was associated with mortality and graft failure [30]. A prospective cohort study of 938 kidney transplant recipients in Hungary showed PTA to be associated with mortality and graft failure at the 4-year follow-up (mortality: HR 1.69; 95\% CI 1.12-2.56; graft failure: HR 2.465; 95\% CI 1.49-4.09) [7]. In a large retrospective analysis of 2,031 transplant recipients in Austria, anemia was significantly associated with mortality and graft failure at a median follow-up of 6 years [5]. A retrospective series of 626 transplant recipients in Pennsylvania, USA, reported that PTA at 12 months was associated with an increased risk of death (HR 3.0; 95\% CI 1.3-6.7) [6]. Another retrospective series of 1,023 transplant recipients conducted in Chicago, IL, USA, PTA after 3 months was associated with mortality and graft failure [31]. In the study conducted by our group

Posttransplantation Anemia including 266 transplant recipients, PTA at 2 years was also associated with increased mortality [1]. In a more recent study of 1,139 patients, PTA at any time point (618 months after transplantation) was associated with the composite endpoint of mortality and graft failure, as well as with each of the components [2]. Another Japanese study [32] and a study from Slovakia showed similar results [33].

Other studies have shown conflicting results regarding long-term mortality. In a retrospective European study of 825 renal transplant recipients, anemia was not associated with all-cause mortality with a follow-up of 8 years [3]. In a multicenter prospective cohort of 2,102 Danish transplant recipients, $\mathrm{Hb}$ levels were not associated with any effect on cardiovascular morbidity or mortality at a 5- to 6-year follow-up [9]. In a retrospective Chinese study of 887 renal transplant recipients, PTA at 12 months was not associated with mortality [34]. In all of these studies anemia was significantly associated with graft loss. Other studies failed to show an association with all-cause mortality, but a significant association with graft loss was demonstrated [35-37].

In the study by our group [2], the association between anemia and mortality was related to severity. Severe ane$\mathrm{mia}(\mathrm{Hb}<11 \mathrm{~g} / \mathrm{dL})$ was consistently associated with mortality (HR 4.36; 95\% CI 3.04-6.27), while mild anemia was not. Both severe and mild anemia were associated with graft failure. These results may explain the discrepancy among studies that showed an association between mortality and anemia and those that did not.

The association between severity and mortality is further emphasized in patients with non-dialysis-dependent chronic kidney disease (CKD) who were predialysis. In a historical prospective cohort of 853 patients with CKD stage 3-5, not yet on dialysis, $\mathrm{Hb}$ values were collected longitudinally over a median follow-up of about 2 years. A time-averaged $\mathrm{Hb}(<11 \mathrm{~g} / \mathrm{dL})$ was associated with a high HR for mortality (HR 2.06; 95\% CI 1.35-3.13) compared to the group with a time-averaged $\mathrm{Hb}>13 \mathrm{~g} / \mathrm{dL}$ [38]. Even patients with a time-averaged $\mathrm{Hb}$ of 11-12 g/ dL had a significantly higher HR for mortality (HR 1.8; 95\% CI 1.23-2.63) compared to the group with a timeaveraged $\mathrm{Hb}$ of more than $13 \mathrm{~g} / \mathrm{dL}$.

\section{Cardiovascular Morbidity}

A retrospective Canadian cohort study conducted in 473 renal transplant recipients showed that anemia and was an independent risk factor for left ventricular hypertrophy (according to Cornell electrocardiographic voltage criteria) 1-5 years after transplantation [11]. Left ven- 
tricular hypertrophy and anemia were associated with a significant risk of death. Another retrospective cohort study conducted in 2 Canadian centers included 638 consecutive adult renal transplant recipients who were free of cardiac disease 1 year after transplantation. Anemia was identified as an independent risk factor for de novo congestive heart failure [10].

\section{GFR Decline}

In the retrospective study by our group, there was a decline of eGFR with time in patients with anemia. There was a difference of $5.26 \mathrm{~mL} / \mathrm{min} / 1.73 \mathrm{~m}^{2}$ in eGFR between 6 months and 2 years. The eGFR in anemic patients declined by $2.26 \mathrm{~mL} / \mathrm{min} / 1.73 \mathrm{~m}^{2}$ while the eGFR increased in nonanemic patients [1]. In the prospective randomized CAPRIT (Correction of Anemia and Progression of Renal Insufficiency in Transplant Patients) trial [12], patients were randomized to receiving epoetin- $\beta$ with a target of $13-15$ or $10.5-11.5 \mathrm{~g} / \mathrm{dL}$. Normalization of PTA to an Hb level of 13-15 g/dL reduced the rate of decline of eGFR and the estimated creatinine clearance, progression to end-stage renal disease (ESRD), and improved death-censored graft survival. This suggests that anemia is associated with a decline of GFR and correction of anemia is associated with a reduction in the rate decline.

This is in accordance with studies of CKD patients. In a cohort of Japanese patients with CKD, a rapid decline of eGFR was strongly associated with anemia [39].

\section{Diagnostic Evaluation}

The diagnostic evaluation of renal transplant recipients should include an assessment for "the usual" causes of anemia as with nontransplanted patients, i.e., red blood cell indices, reticulocyte counts, serum iron, total iron-binding capacity (transferrin), percent transferrin saturation, serum ferritin, folate, and vitamin $B_{12}$, and tests for presence of hemolysis (haptoglobin) when clinically indicated (elevated reticulocyte counts, lactate dehydrogenase, and indirect bilirubin). In addition, specific potential causes of anemia that may be unique to renal transplant recipients, such as the use of medications (immunosuppressive and antimicrobial), concurrent infections, etc., should be sought. Based on published evidence, a full anemia work-up approximately 3 months post transplantation is indicated as early recognition and treatment may improve the prognosis.

\section{Treatment of PTA}

The management of PTA starts with diagnosis and treatment of all reversible causes. As such, treatment should be directed at the underlying cause. However, there is no specific recommendation for the treatment of kidney transplant recipients [40].

Several issues regarding specific treatment should be addressed. Most importantly, the target $\mathrm{Hb}$ level for treatment, followed by the type of treatment, i.e., erythropoiesis-stimulating agents (ESA) and/or iron, should be determined.

In a cross-sectional retrospective cohort study of 1,794 renal transplant recipients in Austria, between 1992 and 2004 , anemia $(\mathrm{Hb}<12.5 \mathrm{~g} / \mathrm{dL})$ was significantly associated with mortality in patients with and without ESA. In patients without ESA, a spontaneous rise in $\mathrm{Hb}$ was associated with decreased mortality at any level. In patients treated with ESA, improvement of anemia (Hb up to 12.5 $\mathrm{g} / \mathrm{dL}$ ) was associated with decreased mortality as well. Further increments in $\mathrm{Hb}$ levels led to a tendency toward increased rates of mortality, which became significant at $\mathrm{Hb}$ levels $>14 \mathrm{~g} / \mathrm{dL}$ [41].

In the CAPRIT trial mentioned above [12] higher $\mathrm{Hb}$ levels were associated with graft survival. In this trial, 125 renal transplant recipients were randomly assigned to receiving epoetin- $\beta$ with a target of $13-15 \mathrm{~g} / \mathrm{dL}$ (complete correction group) or $10.5-11.5 \mathrm{~g} / \mathrm{dL}$ (partial correction group). Normalization of PTA (complete correction to $\mathrm{Hb}$ levels of $13-15 \mathrm{~g} / \mathrm{dL}$ ) with epoetin- $\beta$ reduced the rate of decline of the estimated creatinine clearance, the eGFR, and progression to ESRD and improved death-censored graft survival. Compared to the partial-correction group, the complete-correction group had a smaller decrease in the estimated creatinine clearance (i.e., 5.9 vs. $2.4 \mathrm{~mL} /$ $\mathrm{min} / 1.73 \mathrm{~m}^{2}$ ), a lower rate of ESRD (i.e., 21 vs. $4.8 \%$ ), and a higher death-censored graft survival (i.e., 80 vs. 95\%). There was also a significant improvement in quality of life in the full-correction group. Regarding cardiovascular outcomes, although the numbers were small, there were no cardiac disorders (cardiac failure, arrhythmia, or myocardial infarction) in the full-correction group compared to 4 patients (8\%) in the partial-correction group [12].

The results of the CAPRIT trial are different from those observed in larger trials in the CKD population. The Correction of Hemoglobin and Outcomes in Renal Insufficiency (CHOIR) trial [42] included 1,432 CKD stage 3-4 patients who were randomized to achieve a target $\mathrm{Hb}$ level of 13.5 or $11.3 \mathrm{~g} / \mathrm{dL}$ using epoetin- $\alpha$. The Trial to Reduce Cardiovascular Events with Aranesp Therapy
40

Acta Haematol 2019;142:37-43

DOI: $10.1159 / 000496140$
Gafter-Gvili/Gafter 
(TREAT) included 4,038 patients with type 2 diabetes and CKD stage 3-4 to achieve a target $\mathrm{Hb}$. Patients were randomized to either darbepoetin- $\alpha$ to achieve an $\mathrm{Hb}$ target of $13.0 \mathrm{~g} / \mathrm{dL}$ or placebo with rescue darbepoetin- $\alpha$ when the $\mathrm{Hb}$ concentration was $<9.0 \mathrm{~g} / \mathrm{dL}$ [43]. Both the CHOIR trial and the TREAT demonstrated an increased risk of cardiovascular events and no delay in progressive renal failure by targeting normalization of $\mathrm{Hb}$ with ESA therapy. The Cardiovascular Reduction Early Anemia Treatment Epoetin beta (CREATE) trial [44] was designed similarly to the CAPRIT trial. In that trial, 603 patients with CKD stage 3-5 were randomly allocated to either an $\mathrm{Hb}$ target of 13.0-15.0 g/dL or an $\mathrm{Hb}$ target of 10.5$11.5 \mathrm{~g} / \mathrm{dL}$ using epoetin- $\beta$. It showed that randomization to a higher $\mathrm{Hb}$ target significantly increased the likelihood of initiation of chronic dialysis.

Based on these studies the KDIGO guidelines recommend initiating ESA in patients with CKD only when the $\mathrm{Hb}$ concentration is $<10.0 \mathrm{~g} / \mathrm{dL}$, with a target $\mathrm{Hb}$ level of $11.5 \mathrm{~g} / \mathrm{dL}$ [40]. The National Kidney Foundation-Kidney Disease Outcomes Quality Initiative and targeting (NKFKDOQI) guidelines commented on these guidelines and endorsed the FDA-recommended upper cut-off of $11 \mathrm{~g} /$ dL [45]. Again, no specific recommendation was made for transplant recipients.

The CAPRIT trial in transplanted patients is smaller than all of these trials and it is also limited by its short duration of 2 years. Nevertheless, it is the only randomized controlled trial (RCT) addressing this question in the transplanted population. The results of this study as well as those of the large observational study by Heinze et al. [41] suggest that the optimal target $\mathrm{Hb}$ level in kidney transplant recipients with anemia is higher than the target suggested in CKD and should probably be up to 12-13 g/dL. A larger RCT, designed like the CAPRIT study, with a longer follow-up may help to define the target $\mathrm{Hb}$ level.

As for treatment with iron, in contrast to the abundance of data from RCT and meta-analyses on the efficacy of iron in the CKD population [46], similar studies in transplant recipients are scarce. Iron deficiency, even without anemia, has been shown to be an independent predictor of mortality in renal transplant recipients [26]. Our group conducted a small retrospective cohort study that included 81 patients who received intravenous (i.v.) iron after transplantation between 2000-2009; i.v. iron administration after transplantation increased $\mathrm{Hb}$ levels and reduced the eGFR decline, both of which were more pronounced in lower Hb levels [47].
If ESA is initiated, the iron status should be determined and iron stores should be repleted, as with CKD patients [40]. It is unclear in the transplant setting whether i.v. iron is better than orally administered iron. A small RCT of 104 patients comparing oral administration with a single dose of i.v. iron (i.v. iron polymaltose) after transplantation did not show a difference in time to anemia correction above $11 \mathrm{~g} / \mathrm{dL}$ [48]. However, this trial was conducted in the postoperative period and does not address late PTA. i.v. iron has been shown to be beneficial in the CKD population, both in dialysis and in nondialysis patients [46]. Moreover, a meta-analysis evaluating the safety of i.v. iron for all indications included 103 RCT comparing i.v. iron to another comparator showed that there was no increase in the risk of severe adverse events or serious infections [49]. Therefore, it seems reasonable to treat transplanted patients with i.v. iron.

In conclusion, PTA is a common complication of renal transplant recipients. It is associated with reduced mortality, reduced graft survival, and a decline in GFR. The association with mortality is related to the severity of the anemia. Treatment of PTA should begin as soon as possible after kidney transplantation. Based on data derived from the CAPRIT [12] study and the observational study by Heinze et al. [41], it appears that the optimal target $\mathrm{Hb}$ level in kidney transplant recipients with anemia is higher than the target suggested in CKD and should probably be up to $12.5-13 \mathrm{~g} / \mathrm{dL}$. In order to achieve this target, appropriate treatment with ESA and i.v. iron should be given.

\section{Disclosure Statement}

The authors have no conflict of interests to declare.

References

Acta Haematol 2019;142:37-43

1 Gafter-Gvili A, Cohen E, Avni T, Grossman A, Vidal L, Garty M, et al. Predicting the emergence of anemia - A large cohort study. Eur J Intern Med. 2015 Jun;26(5):338-43.

2 Schechter A, Gafter-Gvili A, Shepshelovich D, Rahamimov R, Gafter U, Mor E, Chagnac A, Rozen-Zvi B. Posttransplantation anemia: causes, severity and their association with graft and patient survival. BMC Nephrol. 2019, in press.

3 Winkelmayer WC, Chandraker A, Alan Brookhart M, Kramar R, Sunder-Plassmann G. A prospective study of anaemia and longterm outcomes in kidney transplant recipients. Nephrol Dial Transplant. 2006 Dec; 21(12):3559-66. 
4 Vanrenterghem Y, Ponticelli C, Morales JM, Abramowicz D, Baboolal K, Eklund B, et al. Prevalence and management of anemia in renal transplant recipients: a European survey. Am J Transplant. 2003 Jul;3(7):835-45.

5 Heinze G, Mitterbauer C, Regele H, Kramar R, Winkelmayer WC, Curhan GC, et al. Angiotensin-converting enzyme inhibitor or angiotensin II type 1 receptor antagonist therapy is associated with prolonged patient and graft survival after renal transplantation. J Am Soc Nephrol. 2006 Mar;17(3):889-99.

6 Imoagene-Oyedeji AE, Rosas SE, Doyle AM, Goral S, Bloom RD. Posttransplantation anemia at 12 months in kidney recipients treated with mycophenolate mofetil: risk factors and implications for mortality. J Am Soc Nephrol. 2006 Nov; 17(11):3240-7.

7 Molnar MZ, Czira M, Ambrus C, Szeifert L, Szentkiralyi A, Beko G, et al. Anemia is associated with mortality in kidney-transplanted patients - a prospective cohort study. Am J Transplant. 2007 Apr;7(4):818-24.

8 Huang G, Wu LW, Yang SC, Fei JG, Deng SX, $\mathrm{Li}$ J, et al. Factors Influencing Graft Outcomes Following Diagnosis of Polyomavirus-Associated Nephropathy after Renal Transplantation. PLoS One. 2015 Nov;10(11):e0142460.

9 Schjelderup P, Dahle DO, Holdaas H, Mjøen G, Nordby G, Abedini S, et al. Anemia is a predictor of graft loss but not cardiovascular events and all-cause mortality in renal transplant recipients: follow-up data from the ALERT study. Clin Transplant. 2013 NovDec;27(6):E636-43.

10 Rigatto C, Parfrey P, Foley R, Negrijn C, Tribula C, Jeffery J. Congestive heart failure in renal transplant recipients: risk factors, outcomes, and relationship with ischemic heart disease. J Am Soc Nephrol. 2002 Apr;13(4): 1084-90.

11 Rigatto C, Foley R, Jeffery J, Negrijn C, Tribula C, Parfrey P. Electrocardiographic left ventricular hypertrophy in renal transplant recipients: prognostic value and impact of blood pressure and anemia. J Am Soc Nephrol. 2003 Feb;14(2):462-8.

12 Choukroun G, Kamar N, Dussol B, Etienne I, Cassuto-Viguier E, Toupance O, et al.; CAPRIT study Investigators. Correction of postkidney transplant anemia reduces progression of allograft nephropathy. J Am Soc Nephrol. 2012 Feb;23(2):360-8.

13 Yorgin PD, Scandling JD, Belson A, Sanchez J, Alexander SR, Andreoni KA. Late posttransplant anemia in adult renal transplant recipients. An under-recognized problem? Am J Transplant. 2002 May;2(5):429-35.

14 Hricik DE. Anemia after kidney transplantation - is the incidence increasing? Am J Transplant. 2003 Jul;3(7):771-2.

15 World Health Organization: Report of a WHO scientific group. WHO Technical Report Series, No 405: 1-40. Geneva: WHO; 1968.
16 Kasiske BL, Vazquez MA, Harmon WE, Brown RS, Danovitch GM, Gaston RS, et al.; American Society of Transplantation. Recommendations for the outpatient surveillance of renal transplant recipients. J Am Soc Nephrol. 2000 Oct;11 Suppl 15:S1-86.

17 Lorenz M, Kletzmayr J, Perschl A, Furrer A, Hörl WH, Sunder-Plassmann G. Anemia and iron deficiencies among long-term renal transplant recipients. J Am Soc Nephrol. 2002 Mar;13(3):794-7.

18 Teruel JL, Lamas S, Vila T, Hernandez RM, Quereda C, Marcen R, et al. Serum ferritin levels after renal transplantation: a prospective study. Nephron. 1989;51(4):462-5.

19 Shibagaki Y, Shetty A. Anaemia is common after kidney transplantation, especially among African Americans. Nephrol Dial Transplant. 2004 Sep;19(9):2368-73.

20 Jimeno L, Rodado R, Campos M, Lanuza M. Iron deficiency - an underrecognized problem in nonanemic and erythrocytic kidney transplant recipients: risks and effects of ACEI and of iron treatment. Transplant Proc. 2005 Mar;37(2):1007-8.

21 Zheng S, Coyne DW, Joist H, Schuessler R, Godboldo-Brooks A, Ercole P, et al. Iron deficiency anemia and iron losses after renal transplantation. Transpl Int. 2009 Apr;22(4): 434-40.

22 Sun CH, Ward HJ, Paul WL, Koyle MA, Yanagawa N, Lee DB. Serum erythropoietin levels after renal transplantation. $\mathrm{N}$ Engl $\mathrm{J}$ Med. 1989 Jul;321(3):151-7.

23 Miles AM, Markell MS, Daskalakis P, Sumrani NB, Hong J, Sommer BG, et al. Anemia following renal transplantation: erythropoietin response and iron deficiency. Clin Transplant. 1997 Aug;11(4):313-5.

24 Saito S, Fujiwara T, Sakagami K, Matsuno T, Tanaka N. Anemia following renal transplantation. Transplant Proc. 1998 Nov;30(7):3025-6.

25 Turkowski-Duhem A, Kamar N, Cointault O, Lavayssiere L, Ribes D, Esposito L, et al. Predictive factors of anemia within the first year post renal transplant. Transplantation. 2005 Oct; 80(7):903-9.

26 Eisenga MF, Minović I, Berger SP, KootstraRos JE, van den Berg E, Riphagen IJ, et al. Iron deficiency, anemia, and mortality in renal transplant recipients. Transpl Int. 2016 Nov; 29(11):1176-83.

27 Karakuş S, Kanbay M, Köseoğlu HK, Colak T, Haberal M. Causes of anemia in renal transplant recipients. Transplant Proc. 2004 JanFeb;36(1):164-5.

28 Mahmud SN, Aziz R, Ahmed E, Akhtar F, Zafar MN, Naqvi A, et al. Anemia characteristics after renal transplantation. Transplant Proc. 2002 Sep;34(6):2428.

29 Gentil MA, Pérez-Valdivia MA, López-Mendoza M, Ortega F, Arias M, Gómez-Alamillo C, et al.; ARES Study Group. Factor deficiency in the anemia of renal transplant patients with grade III-IV chronic kidney disease: baseline results of the ARES Study. Transplant Proc. 2008 Nov;40(9):2922-4.
30 Garrigue V, Szwarc I, Giral M, Soulillou JP, Legendre $\mathrm{C}$, Kreis $\mathrm{H}$, et al. Influence of anemia on patient and graft survival after renal transplantation: results from the French DIVAT cohort. Transplantation. 2014 Jan; 97(2):168-75.

31 Chhabra D, Grafals M, Skaro AI, Parker M, Gallon L. Impact of anemia after renal transplantation on patient and graft survival and on rate of acute rejection. Clin J Am Soc Nephrol. 2008 Jul;3(4):1168-74.

32 Ichimaru N, Obi Y, Nakazawa S, Yamanaka K Kakuta Y, Abe T, et al. Post-Transplant Anemia Has Strong Influences on Renal and Patient Outcomes in Living Kidney Transplant $\mathrm{Pa}$ tients. Transplant Proc. 2016 Apr;48(3):878-83.

33 Majernikova M, Rosenberger J, Prihodova L, Jarcuskova M, Roland R, Groothoff JW, et al. Posttransplant anemia as a prognostic factor of mortality in kidney transplant recipients. Biomed Res Int. 2017;2017:6987240.

34 Huang Z, Song T, Fu L, Rao Z, Zeng D, Qiu Y, et al. Post-renal transplantation anemia at 12 months: prevalence, risk factors, and impact on clinical outcomes. Int Urol Nephrol. 2015 Sep;47(9): 1577-85.

35 Gheith O, Wafa E, Hassan N, Mostafa A, Sheashaa HA, Mahmoud K, et al. Does posttransplant anemia at 6 months affect longterm outcome of live-donor kidney transplantation? A single-center experience. Clin Exp Nephrol. 2009 Aug;13(4):361-6.

36 Kamar N, Rostaing L, Ignace S, Villar E. Impact of post-transplant anemia on patient and graft survival rates after kidney transplantation: a meta-analysis. Clin Transplant. 2012 May-Jun;26(3):461-9.

37 Freiberg M, Chiurchiu C, Capra R, Eckhardt A, De La Fuente J, Douthat W, et al. [Associated factors and clinical implications of post transplant renal anemia]. Medicina (B Aires). 2013;73(2):136-40

38 Kovesdy CP, Trivedi BK, Kalantar-Zadeh K, Anderson JE. Association of anemia with outcomes in men with moderate and severe chronic kidney disease. Kidney Int. 2006 Feb; 69(3):560-4.

39 Chang WX, Arai S, Tamura Y, Kumagai T, Ota T, Shibata $S$, et al. Time-dependent risk factors associated with the decline of estimated GFR in CKD patients. Clin Exp Nephrol. 2016 Feb;20(1):58-70.

40 KDIGO Anaemia Work Group. KDIGO clinical practice guideline for anemia in chronic kidney disease. Kidney Int. 2012;2(Suppl 2): 279-335.

41 Heinze G, Kainz A, Hörl WH, Oberbauer R. Mortality in renal transplant recipients given erythropoietins to increase haemoglobin concentration: cohort study. BMJ. 2009 Oct; 339:b4018

42 Singh AK, Szczech L, Tang KL, Barnhart H, Sapp S, Wolfson M, et al.; CHOIR Investigators. Correction of anemia with epoetin alfa in chronic kidney disease. N Engl J Med. 2006 Nov;355(20):2085-98. 
43 Pfeffer MA, Burdmann EA, Chen CY, Cooper ME, de Zeeuw D, Eckardt KU, et al.; TREAT Investigators. A trial of darbepoetin alfa in type 2 diabetes and chronic kidney disease. $\mathrm{N}$ Engl J Med. 2009 Nov;361(21):2019-32.

44 Drüeke TB, Locatelli F, Clyne N, Eckardt KU, Macdougall IC, Tsakiris D, et al.; CREATE Investigators. Normalization of hemoglobin level in patients with chronic kidney disease and anemia. N Engl J Med. 2006 Nov;355(20): 2071-84.
45 Kliger AS, Foley RN, Goldfarb DS, Goldstein SL, Johansen K, Singh A, et al. KDOQI US commentary on the 2012 KDIGO Clinical Practice Guideline for Anemia in CKD. Am J Kidney Dis. 2013 Nov;62(5):849-59.

46 Shepshelovich D, Rozen-Zvi B, Avni T, Gafter $\mathrm{U}$, Gafter-Gvili A. Intravenous Versus Oral Iron Supplementation for the Treatment of Anemia in CKD: An Updated Systematic Review and Meta-analysis. Am J Kidney Dis. 2016 Nov;68(5):677-90.

47 Rozen-Zvi B, Gafter-Gvili A, Zingerman B, Levy-Drummer RS, Levy L, Mor E, et al. Intravenous iron supplementation after kidney transplantation. Clin Transplant. 2012 JulAug;26(4):608-14.
48 Mudge DW, Tan KS, Miles R, Johnson DW, Badve SV, Campbell SB, et al. A randomized controlled trial of intravenous or oral iron for posttransplant anemia in kidney transplantation. Transplantation. 2012 Apr; 93(8):822-6.

49 Avni T, Bieber A, Grossman A, Green H, Leibovici L, Gafter-Gvili A. The safety of intravenous iron preparations: systematic review and meta-analysis. Mayo Clin Proc. 2015 Jan; 90(1):12-23. 